\title{
An Optimality and Feature Geometry Theoretic account of Spirantisation in Bushehri Dialects
}

\author{
Kord-e Zafaranlu Kambuziya. Aliyeh ${ }^{1}$, Aryaei. Pegah ${ }^{2}$, \\ Bahrami-e khorshid. Sahar ${ }^{3}$ \\ ${ }^{1}$ (Associate Professor of General Linguistics, Tarbiat Modares University, Tehran, Iran.) \\ ${ }^{2}$ (PHD student in General linguistics, Tarbiat Modares University, Tehran, Iran.) \\ ${ }^{3}$ (Assistant Professor of Linguistics, Tarbiat Modares University, Tehran, Iran.) \\ Corresponding author email address: pegah.aryaee@gmail.com
}

\begin{abstract}
This paper intends to illustrate an analysis about spirantization, one of the Common Phonological Processes in some regional varieties of Bushehri, in the framework of Optimality Theory ${ }^{[1]}$ and Feature Geometry Theory ${ }^{[2]}$. Bushehr Province with an area of 23167 square kilometers is located in southern Iran. Speakers in this province can be divided into two general branches: northern and southern branches. Speakers in the northern branch speak a dialect like Luri. Speakers in the southern branch speak dialects that are like what is common in Fars Province. In Bushehri dialects there are four consonants which engage in spirantization process. These consonants include /b, p, d, G/ which are changed to their fricative counterparts [v, f, ð, x]. Kirchner ${ }^{[3: 26]}$ said that "lenition patterns are expressed in terms of conflicts between the effort minimization constraint, LAZY, and on the other hand a class of lenition-blocking constraints. Spirantization, for example, is analyzed in terms of rankings where LAZY dominates IDENT $(\mathrm{x})$. Under the opposite ranking, spirantization is blocked. Clements ${ }^{[2]}$ recognizes that there are three major feature groups, laryngeal features, manner features and place features, which Clements calls Class Nodes. In spirantization process, in the manner node, the feature [continuant] is added to a stop consonant, producing a fricative at the same place.
\end{abstract}

Keywords: Optimality Theory (OT), feature geometry, lenition, spirantization, Bushehr, dialect.

\section{INTRODUCTION}

The purpose of the present study is to provide an overview about one of the common phonological processes in Bushehri dialects: spirantization, and to review the theoretical implications of this process. Bushehr province is located in southern Iran. Northward, it is bounded to Khuzestan and Kohkiluye-Boyer-Ahmad, Eastward to Fars Province, Southward and Westward to the Persian Gulf. Bushehr has 10 counties. Speakers in this province can be divided into two general branches: northern branch that involves Dashtestan, Genaveh, Daylam, Bushehr and some parts of Tangestan county and southern that involve some parts of Bushehr, Dayyer, Jam, Kangan and Tangestan. Speakers in the northern branch speak a dialect like Luri. Speakers in the southern branch speak dialects that are like what is common in Fars Province.

Windfuhr ${ }^{[4: 418]}$ said that: In SW Iran there are two groups which can be recognized as "Preside", i.e. they continue numerous features that evolved from Southern Early New Persian, though each evolved differently:

(1) The Luri-type dialects (Luri proper, Bakhtiari, Boyer-Ahmadi, Mamasani-Kohkiluye).

(2) The Fars dialects stretching from the Persian Gulf into western and central part of Fars.

Fricative is a term used in the phonetic classification of consonant sounds on the basis of their manner of articulation, also sometimes called spirant; it refers to sounds made when two organs come so close together that the air moving between them produces audible friction, or frication. There is no complete closure between the organs (in which case a plosive articulation would be produced): there is simply a stricture, or narrowing. The fricative manner of articulation produces a wider range of speech sounds than any other. They are sounds with a potential for considerable duration (e.g. s-s-s), and, from this point of view, the opposite of fricative (i.e. a continuant sound lacking friction) is called a frictionless continuant. The term spirantization is sometimes used for the process of deriving a fricative from some other type of articulation. ${ }^{[5: 199]}$ Spirantizaton refers to a process in which plosives become fricatives, and this often occurs in environments containing vowels. In

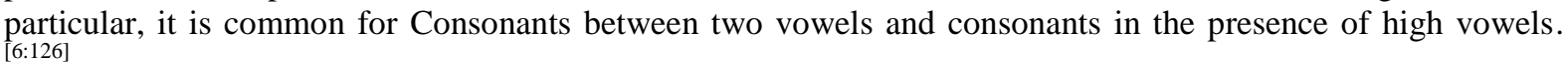

Lenition is a term used in phonology to refer to a weakening in the overall strength of a sound, whether diachronically or synchronically; opposed to fortition. Typically, lenition involves the change from a stop to a fricative, a fricative to an approximant, a voiceless sound to a voiced sound, or a sound being reduced 
(lenite) to zero. For example, the initial mutation in Celtic languages shows lenition in such cases as Welsh pen 'head' becoming ben (his) "head". Both lenition and fortition operate on a segmental level, as opposed to prosodic processes which are located at a supra segmental level. ${ }^{[7]}$ Two types of weakening are distinguished. (a) Consonant weakening (also lenisization): this denotes a weakening of consonant strength (through a reduction in air pressure and muscle tension or an increase in sonority) to the complete loss of a segment [...] (b) vowel weakening: this is a term for all processes that lead to a weakening of the articulatory movement in the sense of an increasing centralization of vowels and finally a total loss of the vowel. ${ }^{[8: 519]}$

Lenition processes increase a segments' sonority and fortition processes decrease it. Sonority is a term in auditory phonetics for the overall loudness of a sound relative to others of the same pitch, stress and duration. Sounds are said to have an 'inherent sonority', which accounts for the impression of a sound's 'carrying further', e.g. [s] carries further than [a], [a] further than [i]. The sonority is typically calculated along a scale from voiceless stops (least) to low vowels (most): voiceless stops - voiced stops - voiceless fricatives - voiced fricatives - nasals - liquids - glides - high vowels - mid vowels - low vowels. ${ }^{\text {[5:442] }}$

The optimality approach ${ }^{[8],[3]}$ advocates articulatory effort as the motivation of lenition and fortition. For instance, fortition is effort-based and driven by a natural need to maximize articulatory effort. ${ }^{[3]}$ Within the NP framework, the lenition/fortition definition is based on the needs of the speaker as well as the listener and offers an operational procedure: if the phonological material is deleted for the benefit of the speaker, it is a lenition; when the material is added for the sake of the listener, it is a fortition.

In this paper, we are going to study spirantization in Bushehri dialects according to the theoretical framework of optimality and feature geometry to answer the following questions: 1) in which one of the consonant of Bushehri dialects, the spirantization process is seen? 2) In which contexts do the spirantization processes apply in this dialect? 3) How we can analyze the data in OT and feature geometry theories?

\subsection{The Consonant and vowel System of Bushehri dialects}

Before the representation of the data, it seems necessary to represent consonants and vowel tables of Bushehri dialects. The phonological system of Bushehri dialects consist of 24 consonants and 7 vowels. The consonant inventory of Bushehri dialects can be classified as follows: eight stops (p, b, t, d, c, J, q, ?); nine fricatives (f, v, s, z, $\int, 3, \mathrm{x}, \gamma, \mathrm{h}$ ); two affricate (d), tf); two nasals (m, n); one lateral (l); one trill (r) and one glide (j). The difference between a phonological system of standard Farsi and Bushehri dialects is that, instead of the voiced uvular consonant $/ \mathrm{G} /$ in standard Farsi, there is voiceless uvular consonant /q/ in Bushehri dialects. Also in Bushehri dialects there is consonant $/ \gamma /$ that Farsi lacks it. In Bushehri 's phonetic system like Farsi, there are two palatal plosives $/ \mathrm{c} /$ and $/ \mathrm{f} /$, but before back vowels they are pronounced $[\mathrm{k}]$ and [g], respectively; such as [kur] "blind", [?angur] "grips". So [k] and [g] are allophones of /c/ and / $\mathrm{g} /$ that make no meaning distinction.

Among the simpler vowel systems in the languages of the world is the standard Farsi vowel system. It is composed of six vowels. Six vowels are generally recognized: three front vowels /i/, /e/ and /a/ and three back vowels /u/, /o/ and /a/. Bushehri dialects vowel system is just like Farsi. In Bushehri dialects, in addition to six vowels of standard Farsi, there is a vowel /ə/. Table (1) illustrates the vowel system in Bushehri dialects.

Table (1) Vowel distinctive features of Bushehri dialects

\begin{tabular}{|c|c|c|c|c|c|c|c|}
\hline & $\mathrm{a}$ & $\mathrm{a}$ & $\mathrm{e}$ & $\mathrm{o}$ & $\mathrm{i}$ & $\mathrm{u}$ & $\partial$ \\
\hline Back & - & + & - & + & - & + & - \\
\hline High & - & - & - & - & + & + & - \\
\hline Low & + & + & - & - & - & - & - \\
\hline Tense & - & + & + & + & + & + & - \\
\hline Round & - & + & - & + & - & + & - \\
\hline
\end{tabular}

\section{THEORETICAL FRAMEWORK AND METHODOLOGY}

The theoretical framework used in this study, namely Optimality Theory (OT), came into existence in early 1990s, mainly focusing on contemporary phonological studies (Prince and Smolensky, 1993; McCarthy and Prince, 1999; Mac Carthy, 2001). This theory was developed as a response to a "conceptual crisis at the center of phonological thought" (Prince and Smolensky, 1993) concerning the role of output constraints. It was also inspired by the concepts of neural networks, as shown by the significance of ideas such as optimization, parallel evaluation, competition, and conflicting constraints which are also present in the framework of OT. Optimality Theory is often considered as a development of generative grammar and the successor of the harmonic grammar developed in 1990s (Legendre et al., 1990, 2001; Prince and Smolensky, 1993; Smolensky and Legendre, 2006). In a typical OT analysis, the phonological constraints are ranked and violable by the phonetic forms of their underlying Representations in a tableau. This is a constraint-based competition system among a possibly infinite set of candidates (at least two) that are actually the potential surface forms of the input. The candidates minimally violate the constraints and the one that incurs the least serious violations in 
terms of hierarchies of constraints, wins. Hence, logically, the violations of higher-ranked constraints are most serious and these violations first oust the concerned candidate from the competition and so on. An OT-style tableau, which uses harmony maximization as the criterion for optimality where the weights are in the top row and the rightmost column, provides the harmony values for the candidates. ${ }^{[9]}$ This framework can effectively analyze various aspects of phonological issues in a language in a comprehensive and systematic manner. An outline of the "classic" OT looks like as follow in (1):

(1) Input $\rightarrow$ GEN $\rightarrow$ candidate set $\rightarrow$ EVAL (constraints) $\rightarrow$ Optimal Output

The method of this research is analytical- descriptive. In order to conduct the study, ten native speakers, selected from different age groups (from 20 to 60 year-old ones) and different educational levels were interviewed. The corpus primarily contains free conversation and life stories.

Here, McCarthy s ${ }^{[1]}$ combination tableau was adapted. The combination tableau illustrates the ranking between constraints, as well as violation marks. In the tableau, each losing $(\mathrm{L})$ candidate is compared to the winning (W) candidate in regards to each constraint. (W) Denotes that the constraint in question prefers the winner rather than the losing candidate. This is why the winner satisfies the constraint, but the losing candidate does not, as specified by the violation mark $(*)$, whereas the $(\mathrm{L})$ denotes that the given constraint is preferred the losing candidate rather than the winner $(\mathrm{W})$.

The theory of feature geometry (cf. [2], [10], etc.) has succeeded in properly analyzing various phonological processes, such as assimilation and harmony, by attributing them to the internal structure of segments. With the advent of Optimality Theory, however, such a structural account seems to be on the wane. Padgett ${ }^{[11]}$, for example, assumes that most features are directly linked to the root node without constituting a hierarchical structure, and that constraint ranking for the most part determines phonological processes. In this paper, I will compare these two theories by providing evidence from spirantization in Bushehri dialects.

\subsection{Spirantization in the Optiamality Theory}

\section{DISCUSSION}

\subsubsection{Spirantization of /d/ to [ð]}

In some of the varieties of Bushehri like Delvari and Dashtestani, there is a process in which voiced stop consonant /d/ changes to counterpart fricative pair [ð] after a vowel, sonorant consonant or in intervocalic place. This process, besides simple words, also occurs between morphemes in a word and in a phrase. When the stop voiced /d/ is located at the beginning of a word, this consonant will be pronounced [d], for example [dast] (hand). But when this word is located after a word with final vowel, intervocalic context is created for voiced stop consonant /d/ and it changes to counterpart fricative pair [ð]. The word [dast] (hand), in the verb [?z. dast raftan] (lose), is pronounced [ðas], because in Dashtestani, this consonant is located after a vowel: [veðas raftan].

Kenstowicz said that "postvocalic context is the most typical environment for the change from stop to fricative (spirantization).this is the environment where Tiberian Hebrew changes its stops [p, t, k] and [b, d, g] to the fricative $[f, \theta, x]$ and $[v, \partial, \gamma]$. "We can see spirantization in the other Iranian dialects such as Bala-Gueriveh Luri dialect. ${ }^{[12: 99-102]}$

Jensen ${ }^{[13: 56]}$ believes that: "lenition literally means weakening. It generally refers to a reduction in the degree of stricture in a sound, roughly along the scales of (a) stops $>$ flaps $>$ fricatives $>$ approximates $>\emptyset$, (b) voiceless aspirated $>$ plain voiceless $>$ voiced. ${ }^{[14: 62]}$ The scale in (a) varies by manner of articulation, while that in (b) involves glottal state." the Table (2):

Examples of spirantization process, which has applied diachronically in Bushehri dialects, are shown in

Table (2) spirantization of /d/ to [ð]

\begin{tabular}{|c|c|c|}
\hline Persian & Bushehri & Gloss \\
\hline bad & bað & wind \\
\hline ra?d & ra:ð & thunder \\
\hline dad & dað & did \\
\hline rud & ruð & darling, dear \\
\hline zoda & xоða & God \\
\hline pedar & peðar & father \\
\hline medad & meðað & pencil \\
\hline zeder & xeðer & a name \\
\hline dzadde & dзaðe & road \\
\hline
\end{tabular}




\begin{tabular}{|c|c|c|}
\hline Jowd & go:ð $^{11}$ & deep \\
\hline bud & bið/ bi & was \\
\hline dud & dið & smoke \\
\hline xaride & xeriðe & she/he is bought \\
\hline savad & so.vað/sevað & literacy \\
\hline pusid & pisiðe & it decayed \\
\hline bidad & biðað & cruelty \\
\hline
\end{tabular}

McCarthy ${ }^{[15: 222]}$ specifies lenition processes in optimality theory with Kirchner s theory (1998) which is a combination of functionalism and structuralism.

Kirchner ${ }^{[3: 26]}$ said that "lenition patterns are expressed in terms of conflicts between the effort minimization constraint, LAZY, and on the other hand a class of lenition-blocking constraints. The lenitionblocking constraints in turn are further divisible into "faithfulness" constraints (penalizing divergence from identity between underlying representation and corresponding surface form)."

(2) LAZY: minimize articulatory effort (i.e. biomechanical energy). ${ }^{[16: 87]}$

Language-specific lenition patterns arise from LAZY, interacting with faithfulness constraints, within an Optimality Theoretic grammar. Spirantization, for example, is analyzed in terms of rankings where LAZY dominates IDENT (x). Under the opposite ranking, spirantization is blocked. The treatment of spirantization in the following tableau, in terms of conflict between LAZY and faithfulness, can trivially be extended to all manner of lenition phenomena. In the Table (3) we can see how LAZY acts in conflict with faithfulness constraint.

Table (3) different consonants violation of LAZY constraint

\begin{tabular}{|c|c|c|}
\hline Lenition degree & Effective causes & Number of stars \\
\hline Deletion & $\varnothing$ & $\emptyset$ (no star) \\
\hline Voiced plosive & No deletion+ plosive & $* *$ \\
\hline Voiceless plosive & No deletion+ plosive+ voiceless & $* * *$ \\
\hline Voiced fricative & No deletion & $*$ \\
\hline Voiceless fricative & No deletion+ voiceless & $* *$ \\
\hline glide & No deletin & $*$ \\
\hline
\end{tabular}

In OT, allophonic variation is captured through the ranking of markedness constraints above faithfulness constraints. The relevant faithfulness constraint is IDENT-IO [continuant], ${ }^{[17]}$ and the relevant markedness constraints can be *VOICED STOP and *[+son, +cont]. But for analyzing the data in table (2) we use three constraints: One is the markedness constraint LAZY and another is a faithfulness constraint IDENT [cont] and the other is IDENT [voice].

(3) IDENT [cont]: Correspondent segments must have the same value of the feature [continuant]. Let $\mathrm{x}$ be a segment in the input and $\mathrm{y}$ a segment in the output. If $\mathrm{xRy}$ and $\mathrm{x}$ is [+/- continuant], then $\mathrm{y}$ is [+/-continuant]. (4) IDENT [voice]: Correspondent segments have identical values for the feature [voice]. Let $\mathrm{x}$ be a segment in the input, and $\mathrm{y}$ a segment in the output. If $\mathrm{xRy}$ and $\mathrm{x}$ is [+/-voice], then $\mathrm{y}$ is [+/-voice].

Tableau (1) presents analyses of the input /pedar/ (father).

Tableau (1) spirantization of /d/ in intervocalic context

\begin{tabular}{|cr|c|c|c|}
\hline \multicolumn{2}{|c|}{$/$ peðar / } & LAZY & $\begin{array}{l}\text { IDENT } \\
\text { [cont] }\end{array}$ & $\begin{array}{l}\text { IDENT } \\
\text { [voice] }\end{array}$ \\
\hline a. & $\rightarrow$ [peðar] & $*$ & $*$ & \\
\hline b. & [ petar] & $* * * \mathrm{~W}$ & $\mathrm{~L}$ & $* \mathrm{~W}$ \\
\hline c. & [pedar] & $* * \mathrm{~W}$ & $\mathrm{~L}$ & \\
\hline \multicolumn{2}{|r|}{} \\
\hline
\end{tabular}

Candidate (a) in Tableau (1) is the winner since it has the least violation of constraint LAZY. About LAZY we can say that the more the process get closer to complete lenition which is the deletion, the less stars it gets. Since Candidate (c) is a stop consonant and it is not deleted, so it receives two stars. Also Candidate (b) is a voiceless stop and it is not deleted, so it violates three times from LAZY and receives 3 stars. In this tableau, if constraint IDENT [cont] was placed in higher ranking, the candidate (c) would be optimal. As a result LAZY

\footnotetext{
${ }^{1}$ The word /fowd/ in Bushehris varieties pronounces as [go:ð]. The deep structure of this word is /fowd/. The Presence of the sonorant consonant $/ \mathrm{w} /$ before plosive $/ \mathrm{d} /$, causes to plosive consonant $/ \mathrm{d} /$ changes to [ð]. After this change, the sonorant consonant $/ \mathrm{w} /$ delete and compensatory lengthening is happening. 
have to have the highest ranking in this tableau. IDENT [cont] and IDENT [voice] are not in conflict with another. This ranking of constraints explains why our data is the optimal and winner candidate. The ranking is as follows:

(5) LAZY >> IDENT [cont]; IDENT [voice]

\subsubsection{Spirantization of $/ \mathrm{b} /$ to $[\mathrm{v}]$}

In Bushehri s varieties, stop voiced /b/ after a vowel or in intervocalic place or at the end of the word, under one kind of lenition processes, spirantization, changes to its fricative counterpart [v]. The data in the Table (4) show that, the stop voiced $/ b /$ in the intervocalic place, as a first member of a consonant cluster or second one, changes to its fricative counterpart $[\mathrm{v}]$ at the end of words. Also, this process is seen in non final position in the Table (4).

Table (4) spirantization of $/ \mathrm{b} /$ to [v]

\begin{tabular}{|c|c|c|}
\hline Persian & Bushehri & Gloss \\
\hline \multicolumn{3}{|c|}{ at the end of the word } \\
\hline nasb & nasv & fitment \\
\hline asb & Pasv & horse \\
\hline sib & siv & apple \\
\hline cetab & cetav & book \\
\hline Galb & qalv & heart \\
\hline hodzb & hodzv & shyness \\
\hline xarab & xerav & spoil \\
\hline tarb & tgarv & gunk \\
\hline $\mathrm{aGrab}$ & Paqrav & scorpion \\
\hline dzib & dgiv & pocket \\
\hline \multicolumn{3}{|c|}{ after a vowel or in intervocalic place } \\
\hline sebil & sevil & moustache \\
\hline zabar & xevar & news \\
\hline nabat & navat & candy \\
\hline abestan & Pavesan & pregnant \\
\hline neJahban & nefa:van & guard \\
\hline tabar & tavar & axe \\
\hline zaban & zavun & tongue \\
\hline tabe & tave/ tava $^{2}$ & fryer \\
\hline xofba $\chi \mathrm{t}$ & xofvaxt & blessed \\
\hline Garbal & yarval & mesh, sieve \\
\hline darban & darvun & doorkeeper \\
\hline mobareze & movareze & battle \\
\hline nabil & nevil & A name \\
\hline necbat & nefvat & calamity \\
\hline sabun & savin & soap \\
\hline zebr & zevr & bristly \\
\hline Gabl & qavl & before \\
\hline lebas & levas & cloth \\
\hline Gabile & qevile & tribe \\
\hline bebax & bevax & forgive \\
\hline torobtfe & torvac & radish \\
\hline cebr & cevr & snooty \\
\hline tabl & tavl & drum \\
\hline mobl & movl & Furniture \\
\hline
\end{tabular}

Both of these tables show that intervocalic place is the lenition context, though at the end of the words or not.

In analyzing the data like previous section, we can use these constraints: LAZY, IDENT [cont], IDENT [voice]. In the following tableau the word /aqrab/ is being analyzed.

\footnotetext{
${ }^{2}$ In Northern dialects, the word /tabe/ (pan), is pronounced as in [tava].
} 


Tableau (2) spirantization of /b/ to [v]
\begin{tabular}{|cc|l|c|c|}
\hline \multicolumn{2}{|c|}{$/$ aqrab/ } & LAZY & $\begin{array}{c}\text { IDENT } \\
\text { [voice] }\end{array}$ & $\begin{array}{c}\text { IDENT } \\
{[\text { cont] }}\end{array}$ \\
\hline a. & $\rightarrow$ [?aqrav] & $*$ & & $*$ \\
\hline b. & {$[$ ?aqraf] } & $* * \mathrm{~W}$ & $* \mathrm{~W}$ & $*$ \\
\hline c. & {$[$ ?aGrab] } & $* * \mathrm{~W}$ & & $\mathrm{~L}$ \\
\hline
\end{tabular}

Analyzing the tableau (2) show that with respect to the least violation of candidate (a) of the constraints in the tableau, this candidate is the winner and optimal. With spirantization of /b/ to its fricative counterpart [v], lenition is occurring, but since there is one step to complete deletion, it receives one star. Candidate (b) has a voiceless fricative consonant and since it is not deleted, it violated from LAZY, 2 times, so it will receive 2 stars. And finally it will be a loser. Also Candidate (c) has 2 violations of LAZY and receives two stars. The ranking is just like previous section.

\subsubsection{Spirantization of /G/ to $[\mathrm{x}]$}

Another kind of spirantization which common in Iranian dialects is the spirantization of voiced plosive /G/ to its fricative counterpart [x]. The data in the following table show this process:

\begin{tabular}{|c|c|c|}
\hline DIe $(5$ & IIIZZato & $/ \mathrm{G} /$ to $[\mathrm{x}]$ \\
\hline persian & Bushehri & Gloss \\
\hline morG $^{3}$ & morx & bird \\
\hline $\mathrm{ma} \int \mathrm{G}$ & $\operatorname{ma} \int x$ & homework \\
\hline vaGt & vaxt & time \\
\hline noGte & noxte & dot \\
\hline taGsir & taxsir & $\sin$ \\
\hline naG $\int \mathrm{e}$ & $\operatorname{nax} \int \mathrm{e}$ & map \\
\hline taGt $\int \mathrm{e}$ & $\operatorname{taxt\int a}$ & sill \\
\hline bejraG & bejrax & banner \\
\hline vaGf & vaxm & glebe \\
\hline saGf & saxf & roof \\
\hline
\end{tabular}

Analyzing the data in that table (6) show that spirantization of $/ \mathrm{G} /$ to $[\mathrm{x}]$ is happening after a vowel or at the end of the word. This process is not happening at the beginning of the word. Also in cases when there is a consonant cluster, and the first member of this cluster is the consonant /G/, the second member is one of the obstruent consonant such as $\left\{\int, \mathrm{f}, \mathrm{t}, \mathrm{s}\right\}$, as all of them have to share the feature [-sonority]. This context is the right context for the lenition.

Bijan khan ${ }^{\text {[18: } 192]}$ said that: "the contrast between /G/ and / $\mathrm{x} /$ is stable in all phonological contexts, except when the consonant /G/ is placed before a voiceless alveolar obstruent consonant. For example, in the words /vaGt/ (time), /noGte/ (dot), /raGs/ (dance) and /taGsir/ (guilt), the contrast between these two consonants is neuter and $/ \mathrm{G} /$ changes to $/ \mathrm{x} / . "$

Now we can analyze the word /naGs/ (defect) in the following tableau according to the constraints which is introduced before.

Tableau (3) Spirantization of $/ G /$ to $[\mathrm{x}]$

\begin{tabular}{|c|c|c|c|c|c|}
\hline \multicolumn{2}{|c|}{ /naqs/ } & LAZY & AGREE & IDENT & IDENT \\
\hline a. & $\rightarrow[$ naxs $]$ & $* *$ & & $*$ & $*$ \\
\hline b. & [naks] & $* * * \mathrm{~W}$ & & $*$ & * \\
\hline c. & [naGs] & $* *$ & $* \mathrm{~W}$ & $\mathrm{~L}$ & $\mathrm{~L}$ \\
\hline
\end{tabular}

Candidate (b) in the tableau (3) is the loser since it is a voiceless plosive consonant and it is not deleted, so it has 3 times violations of the constraint LAZY. Among the rest of the candidates, the candidate (a) and (c), both have two time violations of markedness constraint LAZY. The cause of violation of LAZY for Candidate (a) is being voiceless and having one step distance to delete which is a complete degree of lenition, and the cause of the violation for candidate (c) is being plosive and not deleted. Now these two candidates will be analyzed according to AGREE [voice] which is another markedness constraint. It is assumed that assimilation between

\footnotetext{
${ }^{3}$ In bushehri dialects, Instead of voiced uvular plosive /G/, its voiceless counterpart /q/ is used.for this reason the deep structure of these words is as follow: /aqrav/ ‘/morq/ ‘/mafq/ ‘/vaqt/, ....

DOI: $10.9790 / 0837-2205018392 \quad$ www.iosrjournals.org $\quad 88$ Page
}


adjacent segments is driven by the family of agreement constraints, ${ }^{[19]},{ }^{[20]},{ }^{[21]}$; see also ${ }^{[22]}$ and ${ }^{[23], ~[24] .}$ This constraint said that adjacent segments must share the same value for the feature [voice]. According to Baković ${ }^{[25: 337]}$ the need for ranking AGREE [x] above IDENT [x] for the sake of guaranteeing assimilation will be shown in a tableau. Since in the candidate (a) two final consonants have the same feature of [-voice], there is no violation of AGREE [voice] and it is the winner and the optimal candidate. This ranking of constraints explains why our data is the optimal and winner candidate. The ranking is as follows:

(6) LAZY >> AGREE [voice] >> IDENT [cont]; IDENT [voice]

\subsubsection{Spirantization of /p/ to [f]}

Another kind of spirantization in Bushehris dialect is the spirantization of /p/ to [f].

Table (6) spirantization of $/ \mathrm{p} /$ to [f]

\begin{tabular}{|c|c|c|}
\hline Bushehri & persian & Gloss \\
\hline cafsul & capsul & capsule \\
sefiðe & sepide & white \\
sufur & sopur & dustman \\
sefiðar & sepidar & poplar \\
cefac & capac & mold \\
helikufter & helicupter & copter \\
kaffan & capfan & parka \\
Jejfur & Sejpur & horn \\
\hline
\end{tabular}

In analyzing the data in the Table (6), we can use three constraints: LAZY, IDENT [cont], IDENT [voice]. In the tableau (4) the word /capac/ will be analyzed.

Tableau (4) spirantization of $/ \mathrm{p} /$ to [f]

\begin{tabular}{|cr|c|c|c|}
\hline \multicolumn{2}{|c|}{$/$ cafac/ } & $\begin{array}{l}\text { IDENT } \\
\text { [voice] }\end{array}$ & LAZY & $\begin{array}{c}\text { IDENT } \\
\text { [cont] }\end{array}$ \\
\hline a. & $\rightarrow[$ cafac] & & $* *$ & $*$ \\
\hline b. & {$[$ capac] } & & $* * * \mathrm{~W}$ & $\mathrm{~L}$ \\
\hline c. & {$[$ cavac] } & $* \mathrm{~W}$ & $* \mathrm{~L}$ & $*$ \\
\hline
\end{tabular}

In the tableau (4), the candidate (c), have one violation of LAZY constraint with changing the consonant $/ \mathrm{p} /$ to $[\mathrm{v}]$ and one violation of IDENT [voice] with changing the voice feature. As a result this candidate will be out of the competition at the beginning. The other candidate will continue the competition with regard to LAZY. The candidate (b) has three time violations of LAZY, because the candidate (b) is a voiceless plosive consonant and it has one step to deletion. So candidate (b) in comparative to candidate (a) which has two violations of LAZY is the loser and finally, the candidate (a) is the optimal candidate. We can see that just in this kind of spirantization, LAZY hasn't the highest ranking in the tableau (4) and the IDENT [voice] is the dominant constraint. The final ranking is as follows:

(7) IDENT [voice]>> LAZY >> IDENT [cont]

\subsection{Spirantizaition in the Feature Geometric Theory}

Let us now move on to an analysis within the gestural theory. As mentioned above, more and more researchers in Optimality Theory are abolishing the idea of feature geometry, proposing instead that properlyranked constraints alone can account for the data that feature geometry had analyzed in derivational theory (cf. Pullyblank (1997), Suzuki (1998), Fukazawa (1999), Yip (2003), etc.).

A segment is not just an unorganized bundle of features, but that features have their own internal organization. This is well reflected in feature geometry theory proposed by many researchers including ${ }^{[2]}{ }^{[10]}$, Halle (1986, 1989), McCarthy (1988) and others.

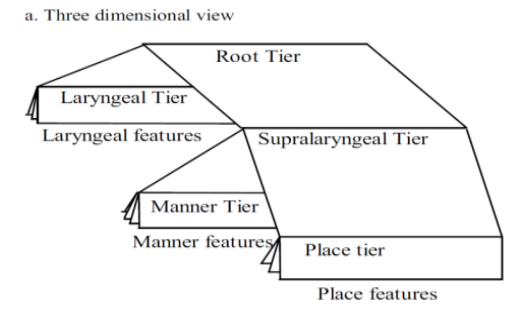




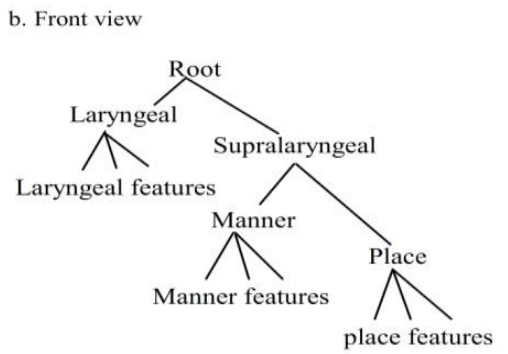

Figure 1. Clements' ${ }^{[2]}$ Feature Geometry

As shown in (Fig.1.a, b), Clements ${ }^{[2]}$ recognizes that there are three major feature groups, laryngeal features, manner features and place features, which Clements calls Class Nodes. He also assumes that the Manner Node and Place Node are combined together to make another internal hierarchical group under the Supra laryngeal Node. Clements uses the term tier to refer to the internal structural unit. Two tiers constitute a plane and phonological rules can be expressed as changes in association lines on specified planes. Similarly, Halle ${ }^{[26]}$ groups features according to the particular articulators that are involved in executing those features and comes up with the Laryngeal Node, the Place Node and the Soft Palate Node as shown in (Fig.2):

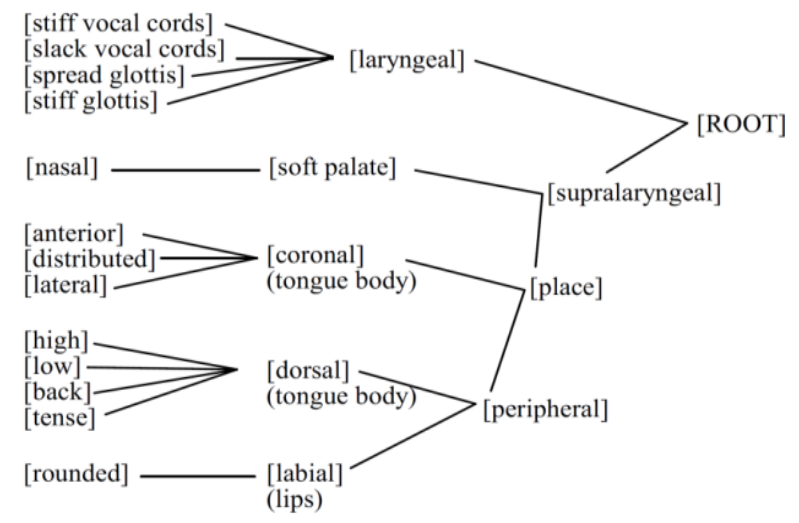

Figure 2. Halle's ${ }^{[26]}$ Feature Geometry

Halle's ${ }^{[26]}$ Feature Geometry, unlike Clements', does not have the Manner Node. Halle assumes that [nasal] and [lateral] are separate features that do not make up a natural class. Nonetheless, there is general agreement among researchers (including Halle and Clements) that there are at least a place node and a laryngeal node.

Clements, ${ }^{[2]}$ groups all the manner features together under a manner node and groups the manner node with the place node under the supra laryngeal node as shown in (Fig.3). Here are Clements' ${ }^{[2]}$ manner features and the location of the manner node in FG.

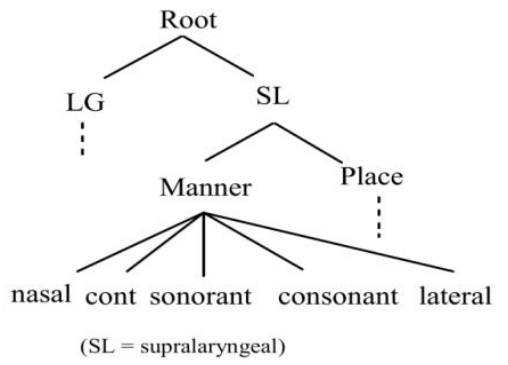

Figure 3. Manner feature and manner node in Clements ${ }^{[2]}$

There are, however, several pieces of evidence which suggest that [cont] does act independently. Grimm's Law and Verner's Law, which were very productive in Germanic languages, illustrate the point:

(8)

a. Grimm's Law: $p, t, k \rightarrow f, \theta, x$

b. Verner's Law: $p, t, k \rightarrow f, s, x$ 
Both of these historical processes are analyzed quite simply as the addition of [cont], or spirantization.

According to the Fig (4), all kinds of the spirantization in Bushehri dialect can be analyzed. For example spirantization of $/ \mathrm{b} /$ to $[\mathrm{v}]$ :

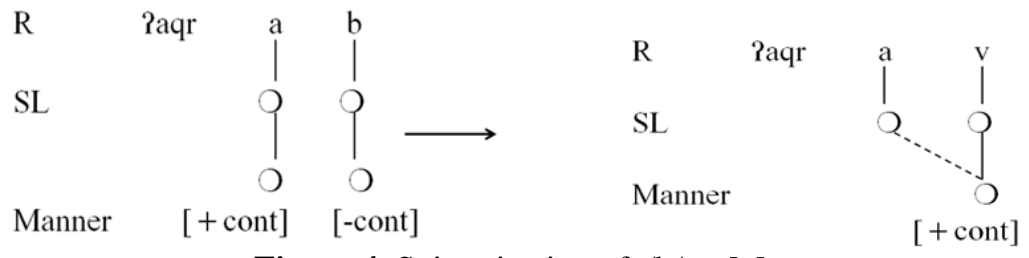

Figure 4. Spirantization of $/ b /$ to $[v]$

As can be seen in feature (4), in this process, feature [continuant] is added to a stop consonant, producing a fricative at the same place.

\section{CONCLUSION}

In Bushehri dialects there are four consonants which engage in spirantization process. One is the voiced stop consonant /d/ which is changed to counterpart fricative pair [ð] after a vowel, sonorant consonant or in intervocalic place, the other is the stop voiced /b/ which changes to its fricative counterpart [v], after a vowel or in intervocalic place or at the end of the word. And the other two consonants are $/ \mathrm{G} /$ and $/ \mathrm{p} /$ which are changed to their fricative counterpart $[\mathrm{x}]$ and $[\mathrm{f}]$.

Mac Carthy ${ }^{[15: 222]}$ specifies lenition processes in optimality theory with Kirchner's theory ${ }^{[3]}$ which is a combination of functionalism and structuralism.

Lenition patterns are expressed in terms of conflicts between the effort minimization constraint, LAZY, and on the other hand a class of lenition-blocking constraints. ${ }^{[3: 26]}$ Language-specific lenition patterns arise from LAZY, interacting with faithfulness constraints, within an Optimality Theoretic grammar. Spirantization, for example, is analyzed in terms of rankings where LAZY dominates IDENT (x). Under the opposite ranking, spirantization is blocked.

Also we saw that Clements ${ }^{[2]}$ recognizes that there are three major feature groups, laryngeal features, manner features and place features, which Clements calls Class Nodes. In spirantization process, in the manner node, [continuant] is added to a stop consonant, producing a fricative at the same place.

\section{REFRENCES}

[1] J. McCarthy, Doing optimality theory: Applying theory to data (Malden, MA: Blackwell Publishing. doi: 10. 1002/9781444301182, 2008).

[2] G. N. Clements, The Geometry of Phonological Features, Phonology Yearbook 2,. Cambridge university press, 1985, 225-252

[3] R. Kirchner, An effort-based approach to consonant lenition, Doctoral dissertation. UCLA, 1998.

[4] G. Windfuhr, The Iranian Languages (Rutledge, Taylor \& Francis Group, London and New York, 2009).

[5] D. Crystal, A Dictionary of Linguistics and Phonetics (Oxford: Blackwell, 2008).

[6] D. A. Burquest, Phonological Analysis, a Functional Approach, Dallas: SIL International, 2001.

[7] H. C. Luschützky, Sixteen possible types of natural phonological processes, in: Charles W. Kreidler (ed), 2001, 506-524.

[8] H. Bussmann,., Rutledge Dictionary of Language and Linguistics (Taylor \& Francis e-Library, 1996, 2006)

[9] S. Kar, Gemination in Bangla: An Optimality-theoretic analysis, The Dhaka University Journal of Linguistics 1 (2), 2009, 87-114.

[10] E. Sagey, The Representations of Features and Relations in Non-linear Phonology, Doctoral dissertation, MIT. 1986.

[11] J. Padgett, Feature Classes, University of Massachusetts Occasional Papers 18: Papers in Optimality Theory, ed. by Jill N. Beckman, Laura Walsh Dickey and Suzanne Urbanczyk, GLSA, University of Massachusetts, Amherst, $1995,385-420$.

[12] A. Solejmani, Phonological processes of Bala-Gueriveh Luri dialect: an Optimality Approach. Thesis for master of art in linguistics., Tarbiat Modares university. Iran. 2012.

[13] J. T. Jensen, Principles of Generative Phonology: An Introduction (John Benjamin's Publishing Company, 2004).

[14] A. Spencer, A, Phonology (Oxford: Blackwell, 1996).

[15] J. McCarthy, A Thematic Guide to Optimality Theory (Cambridge: Cambridge University Press, 2002).

[16] R. Kirchner, An Effort Based-Approach to Consonant Lenition (New York. Rutledge, 2001). 
[17] J. McCarthy and A. Prince, Faithfulness and reduplicative identity, Papers in Optimality Theory, In J. Beckman, S. Urbanczyk and L. Walsh Dickey (eds.), Amherst, MA: Graduate Linguistics Students Association, University of Massachusetts, 1995, 249-384 [ROA216, http://roa.rutgers.edu].

[18] M. Bijan khan, Phonology: Optimality Theory (Samt: Tehran, 2010).

[19] L. Lombardi, Positional Faithfulness and Voicing Assimilation in Optimality Theory, Ms., University of Maryland, College Park.1996 a.

[20] L. Lombardi, Restrictions on direction of voicing assimilation: an OT account, University of Maryland Working Papers in Linguistics, 1996b, 4, 84-102. [ROA- 247.]

[21] L. Lombardi, Positional Faithfulness and Voicing Assimilation in Optimality Theory. NLLT 17, 1999, 267-302.

[22] J. Beckman, Positional Faithfulness, Positional Neutralization and Shona Vowel Harmony. Phonology, 1998, 14, 1-46.

[23] E. Bacovic, Harmony, Dominance and Control. Doctoral dissertation, Rutgers University: New Brunswick, NJ. [ROA-360]. 2000.

[24] L. Butska, 1998, Faithfulness to [voice] in Ukrainian: An Analysis of Voicing Alternations within Optimality Theory, In R. Artstein and M. Holler (Eds.), RuLing Papers 1 (Working Papers from Rutgers University), 1998, 59-73.

[25] E. Bakovic, E., (2007). Local Assimilation and Constraint Interaction, de Lacy (ed.), The Cambridge Handbook of Phonology, Cambridge University Press, 2007, 335-352.

[26] M. Halle, phonological features, International Encyclopedia of Linguistics, Oxford: Oxford University Press: vol. 3, 1992, pp 207-12. 